\title{
Preparation and Characterization of Cellulose Acetate Film Reinforced with Cellulose Nanofibril
}

\author{
Azelia Wulan Cindradewi ${ }^{1}$, Rajkumar Bandi ${ }^{2} \mathbb{D}$, Chan-Woo Park ${ }^{2} \mathbb{D}$, Ji-Soo Park ${ }^{1,3}$, Eun-Ah Lee ${ }^{1}$, \\ Jeong-Ki Kim ${ }^{1}$, Gu-Joong Kwon ${ }^{2,4}$, Song-Yi Han ${ }^{2}$ and Seung-Hwan Lee ${ }^{1,2, *(D)}$ \\ 1 Department of Forest Biomaterials Engineering, Kangwon National University, \\ Chuncheon 24341, Korea; azeliacindradewi@gmail.com (A.W.C.); pojs04@kangwon.ac.kr (J.-S.P.); \\ laa3158@kangwon.ac.kr (E.-A.L.); panda20@kangwon.ac.kr (J.-K.K.) \\ 2 Institute of Forest Science, Kangwon National University, Chuncheon 24341, Korea; \\ rajkumar.pgcb@gmail.com (R.B.); chanwoo8973@kangwon.ac.kr (C.-W.P.); \\ gjkwon@kangwon.ac.kr (G.-J.K.); songyi618@kangwon.ac.kr (S.-Y.H.) \\ 3 National Institute of Forest Science, Seoul 02455, Korea \\ 4 Kangwon Institute of Inclusive Technology, Kangwon National University, Chuncheon 24341, Korea \\ * Correspondence: lshyhk@kangwon.ac.kr; Tel.: +82-33-250-8323
}

check for updates

Citation: Cindradewi, A.W.; Bandi, R.; Park, C.-W.; Park, J.-S.; Lee, E.-A.; Kim, J.-K.; Kwon, G.-J.; Han, S.-Y.; Lee, S.-H. Preparation and Characterization of Cellulose Acetate Film Reinforced with Cellulose Nanofibril. Polymers 2021, 13, 2990. https://doi.org/10.3390/ polym 13172990

Academic Editor: Sergio Torres-Giner

Received: 4 August 2021

Accepted: 1 September 2021

Published: 3 September 2021

Publisher's Note: MDPI stays neutral with regard to jurisdictional claims in published maps and institutional affiliations.

Copyright: (c) 2021 by the authors. Licensee MDPI, Basel, Switzerland. This article is an open access article distributed under the terms and conditions of the Creative Commons Attribution (CC BY) license (https:/ / creativecommons.org/licenses/by/ $4.0 /)$.

\begin{abstract}
In this study, cellulose acetate (CA)/cellulose nanofibril (CNF) film was prepared via solvent casting. CNF was used as reinforcement to increase tensile properties of CA film. CNF ratio was varied into 3, 5, and $10 \mathrm{phr}$ (parts per hundred rubbers). Triacetin (TA) and triethyl citrate (TC) were used as two different eco-friendly plasticizers. Two different types of solvent, which are acetone and N-methyl-2-pyrrolidone (NMP), were also used. CA/CNF film was prepared by mixing CA and CNF in acetone or NMP with 10\% concentration and stirred for $24 \mathrm{~h}$. Then, the solution was cast in a polytetrafluoroethylene (PTFE) dish followed by solvent evaporation for $12 \mathrm{~h}$ at room temperature for acetone and $24 \mathrm{~h}$ at $80^{\circ} \mathrm{C}$ in an oven dryer for NMP. The effect of solvent type, plasticizers type, and $\mathrm{CNF}$ amount on film properties was studied. Good dispersion in NMP was evident from the morphological study of fractured surface and visible light transmittance. The results showed that CNF has a better dispersion in NMP which leads to a significant increase in tensile strength and elastic modulus up to $38 \%$ and $65 \%$, respectively, compared with those of neat CA. CNF addition up to $5 \mathrm{phr}$ loading increased the mechanical properties of the film composites.
\end{abstract}

Keywords: cellulose acetate; cellulose nanofibril; eco-friendly plasticizer; film casting

\section{Introduction}

Cellulose is a bio-based plastic polymer that can be derived from biomass. Thus, it is highly available. Cellulose-derived products such as cellulose acetate (CA), cellulose acetate propionate (CAP), and cellulose acetate butyrate (CAB) have been used in many industries such as automotive, biomedical, coatings, and packaging [1]. Among all the cellulose-derived products, cellulose acetate (CA) is the one that has been widely produced for thermoplastics. Cellulose acetate was successfully applied for the preparation of membranes in different membrane technologies [2], for wastewater treatment containing heavy metals or metallic ions [3,4], film packaging [5], in the textile industry [6], medical engineering [7], and in gas separation [8]. CA is prepared through acetylation of cellulose with an excessive amount of acetic anhydride by a sulfuric acid catalyst. The biodegradability of CA is based on its acetylation degree; CA with a low acetylation degree or substitution degree (DS: $\leq 2.5)$ can be degraded. CA is highly available, biodegradable, biocompatible, and relatively low-cost [9].

Considering these advantages, CA can be considered as a promising biodegradable plastic material that can serve an alternative for fossil-based plastic. However, CA has high stiffness and CA with DS around 2.5 has a narrow window between the melting point and the degradation temperature [10]. These properties are limiting the use of CA for wider 
applications. The use of a plasticizer can reduce the glass transition temperature of CA and also decrease the intermolecular force among the polymer chains, resulting in a softened and more flexible polymeric matrix [11].

Phthalate esters are the most common industrially used plasticizers for CA. However, they have been subjected to environmental scrutiny as a health threat, and thus there is now serious concern about their long-term use [12]. To improve the processing of CA, some studies have explored several eco-friendly plasticizers such as Triacetin (TA), triethyl citrate (TC), glycerol, and polyethylene glycol (PEG) $[13,14]$. These plasticizers are biodegradable, non-toxic, and have been approved as a plasticizer for many polymers. TA and TC are two of the most common eco-friendly plasticizers that have been used for CA. TA and CA share the same side functional groups: acetyl groups. TC is proved to be able to improve the stiffness and brittle of CA films $[15,16]$. Plasticizer addition into the CA matrix will decrease the tensile strength $[16,17]$. Therefore, it could impede the function of CA bio-plastics in specific industries. For this reason, the use of reinforcement or filler is needed to improve the tensile strength of CA [17]. Several studies have been conducted to improve the mechanical properties of CA using organo-clay, zeolite, microfiber, lignin, and nanocellulose as reinforcement $[18,19]$.

Cellulose nanofibril (CNF) is one type of nanocellulose that contains long, flexible, and entangled fiber [20]. It has several advantages such as high tensile properties and high specific surface area, and being renewable and biodegradable [21]. CNF is considered as a potential reinforcing filler for manufacturing composites as it is renewable, lightweight, and cost effective [22,23]. Moreover, it also has high young's modulus and tensile properties [24]. Despite these advantages, uniform dispersion of CNF in CA matrix is challenging. Dispersing CNF in the same organic solvent with CA is one method that can be taken to obtained good dispersion of CNF in CA matrix. Several studies have mentioned good dispersion of nanocellulose in some organic solvents such as dimethylsulfoxide (DMSO), dimethylformamide (DMF), and N-methyl-2-pyrrolidone (NMP) $[25,26]$. Berg et al., in 2007, found that NMP performs a faster dispersion process compared with DMF or DMSO [25].

In this study, CA was plasticized using two different kinds of eco-friendly plasticizers, TA and TC. Plasticized CA was then reinforced with CNF to improve the mechanical properties of the composite. CA film was prepared with a solvent casting method using two different solvents (acetone and NMP). The effect of plasticizer type, solvent type, and $\mathrm{CNF}$ amount on film properties were investigated. The novelty of the present work lies in the manufacture and comparison of the properties of new CA/CNF films using two different solvents so as to indicate the better solvent for film making.

\section{Materials and Methods}

Commercial CNF (3.9 wt\% in water) was supplied by Cellulose Lab, Co., Ltd. (Fredericton, NB, Canada). Cellulose acetate (39.8 wt \% acetyl content, DS 2.5, and average molecular weight $\mathrm{Mn} \sim 30,000)$, acetone (99.8\% purity), triacetin (99.5\% purity), and N-Methyl-2pyrrolidone (NMP) were purchased from Daejung Chemical \& Metals Co., Ltd. (Siheung, Korea). Triethyl citrate (99.0\% purity) was purchased from TCI chemicals (Seoul, Korea).

CNF was solvent-exchanged from water to acetone or NMP using centrifugation at $18,000 \mathrm{rpm}$ for $15 \mathrm{~min}$ followed by re-dispersion in the new solvent. Centrifugation was repeated at least 6 times to ensure all the water was exchanged.

Films were prepared by solvent casting technique on a polytetrafluoroethylene (PTFE) dish (graphical illustration is shown in Scheme 1). 


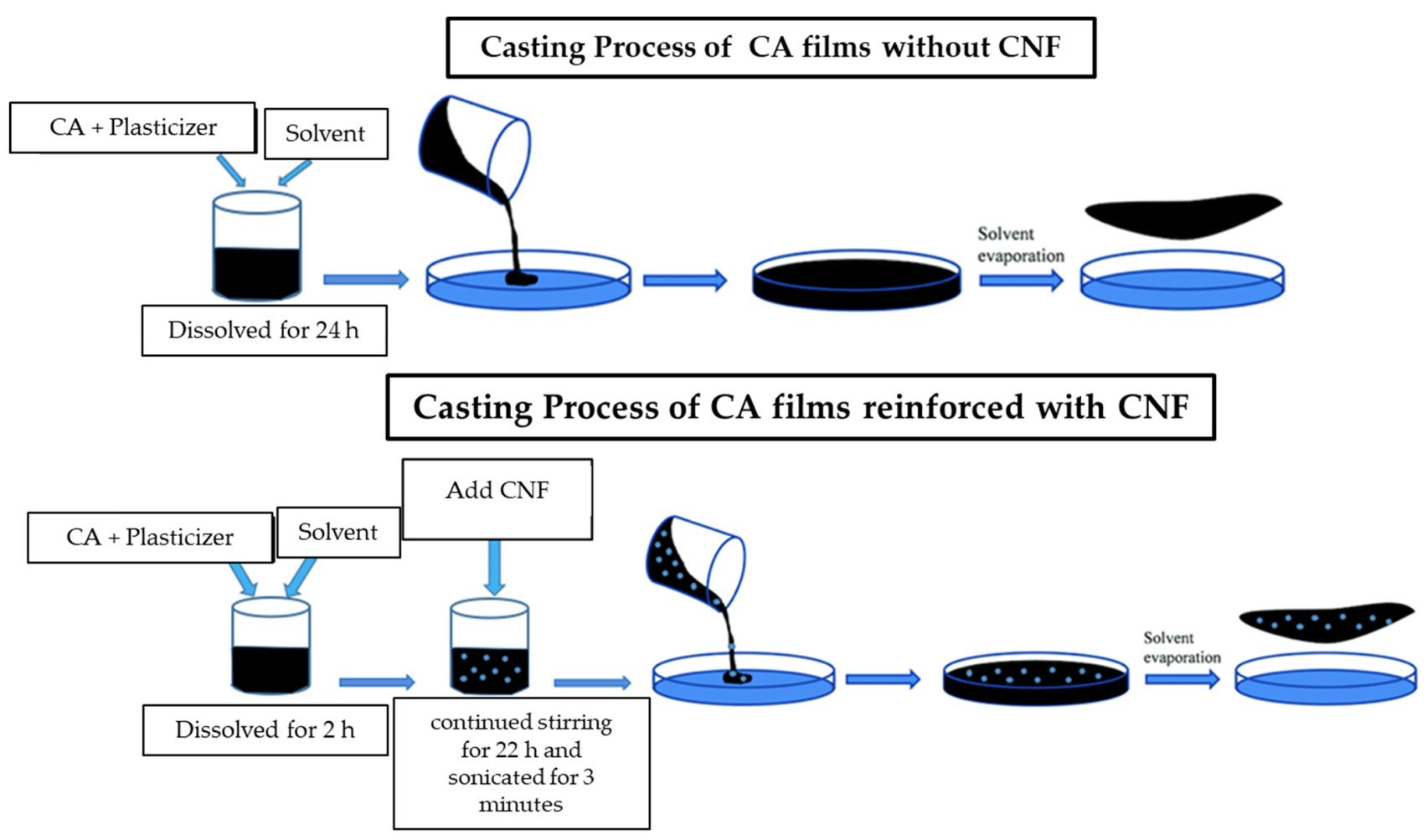

Scheme 1. Schematic diagram of CA film preparation with and without CNF.

$\mathrm{CA}$ and plasticizer were dissolved in acetone or NMP solvent with $10 \mathrm{wt} \%$ concentration and then mixed for $2 \mathrm{~h}$ until homogenized. CNF in the same solvent was added with concentrations of 3,5 , and 10 parts per hundred rubbers (phr). The mixture was homogenized by magnetic stirring for $22 \mathrm{~h}$ continued with $3 \mathrm{~min}$ sonication. Then, plasticized CA/CNF solution was poured into the PTFE dish and solvent was evaporated by keeping at room temperature for $12 \mathrm{~h}$ for acetone and at $80{ }^{\circ} \mathrm{C}$ for $24 \mathrm{~h}$ for NMP. Neat $\mathrm{CA}$ and plasticized CA without CNF were also prepared using the same method with magnetic stirring for $24 \mathrm{~h}$. Table 1 describes sample compositions for both acetone and NMP solvents.

Table 1. Sample compositions (applied to both acetone and NMP solvents).

\begin{tabular}{|c|c|c|c|c|}
\hline \multirow{2}{*}{ Sample Name } & \multicolumn{3}{|c|}{ Compositions (wt\%) Weight } & \multirow{2}{*}{ CNF (phr) } \\
\hline & $\mathrm{CA}$ & TA & TC & \\
\hline CA & 100 & - & - & - \\
\hline \multirow{3}{*}{$\mathrm{CA} / \mathrm{TA}$} & 80 & 20 & - & - \\
\hline & 70 & 30 & - & - \\
\hline & 60 & 40 & - & - \\
\hline \multirow{3}{*}{$\mathrm{CA} / \mathrm{TC}$} & 80 & - & 20 & - \\
\hline & 70 & - & 30 & - \\
\hline & 60 & - & 40 & - \\
\hline $\mathrm{CA} / \mathrm{TA} / \mathrm{CNF3}$ & 70 & 30 & - & 3 \\
\hline CA/TA/CNF5 & 70 & 30 & - & 5 \\
\hline CA/TA/CNF10 & 70 & 30 & - & 10 \\
\hline $\mathrm{CA} / \mathrm{TC} / \mathrm{CNF3}$ & 70 & - & 30 & 3 \\
\hline CA/TC/CNF5 & 70 & - & 30 & 5 \\
\hline CA/TC/CNF10 & 70 & - & 30 & 10 \\
\hline
\end{tabular}


Mechanical properties of the neat CA film, CA/TA, CA/TC, CA/TA/CNF, and $\mathrm{CA} / \mathrm{TC} / \mathrm{CNF}$ films were measured using a universal testing machine (UTM test one Model TO-102D, Siheung, South Korea) with a cross-head speed of $10 \mathrm{~mm} / \mathrm{min}$. A specimen span length was set at $30 \mathrm{~mm}$. Samples were cut into dog-bone shapes as described by the American Society for Testing and Materials (ASTM D638) [27]. At least 5 specimens of each sample were tested, and the average values were taken. All of the tests were performed at $25{ }^{\circ} \mathrm{C}$ and $40 \%$ relative humidity.

The water absorption test was conducted based on the American Society for Testing and Materials (ASTM) D570 as the Standard Test Method for Water Absorption of Plastics [28]. Film specimens were dried in an oven for $24 \mathrm{~h}$ at $50{ }^{\circ} \mathrm{C}$ and then cooled in a desiccator, and immediately weighted to the nearest $0.001 \mathrm{~g}$. The conditioned specimens were then placed in a container of distilled water at a temperature of $23{ }^{\circ} \mathrm{C}$, resting on the edge, and were entirely immersed for $24 \mathrm{~h}$. All the specimens were removed from the water at a time, and then surface water was wiped off with a dry tissue paper and they were immediately weighted to the nearest $0.001 \mathrm{~g}$. The percentage of water absorption was determined by the following Equation (1):

$$
\text { Water absorption }(\%)=\frac{(\text { wet sample weight }- \text { dry sample weight })}{\text { dry sample weight }} \times 100 \%
$$

Thermal stability of neat CA, CA/TC, and CA/TC/CNF5 films was investigated using a TG analyzer (Q2000, TA Instruments Inc., New Castle, DE, USA) in the Central laboratory of Kangwon National University. The samples (5-10 mg) were heated on a platinum pan under a nitrogen atmosphere. The scanning temperature range was set from 25 to $700{ }^{\circ} \mathrm{C}$, with a heating rate of $10^{\circ} \mathrm{C} / \mathrm{min}$. The derivative TG (DTG) analysis was obtained by measuring the mass loss percentage with respect to temperature.

The viscosity of the CA/TC, CA/TC/CNF3, CA/TC/CNF5, and CA/TC/CNF10 samples was measured using a digital viscometer (DV-II+, Brookfield Engineering Laboratories, Middleborough, MA, USA). The temperature was maintained at $25^{\circ} \mathrm{C}$. The viscosity was measured with SC4-18 spindle at a range of shear rates from 0.4 to $132 \mathrm{~s}^{-1}$.

Fractured surfaces of CA/TC, CA/TC/CNF5, and CA/TC/CNF10 prepared in NMP samples were examined using a scanning electron microscope (SEM, S-4800, Hitachi, Ltd., Tokyo, Japan) in the Central Laboratory of the Kangwon National University. Samples were cryo-fractured using liquid nitrogen and directly used. Before the observation, the surfaces were sputter-coated with a platinum layer using a high-vacuum sputter coater (EM ACE600, Leica Microsystems, Ltd., Wtzlar, Germany) to avoid charging under the electron beam. The morphologies were observed at an accelerating voltage of $5 \mathrm{kV}$ with a working distance of $8.5 \mathrm{~mm}$.

CNF sample for SEM analysis was prepared with the following method. CNF suspensions were diluted to $0.1 \mathrm{wt} \%$ and then dispersed using an ultrasonicator (VCX130PB, Sonics \& Materials Inc., Newtown, CT, USA) for $1 \mathrm{~min}$. The suspensions were then filtrated on a polytetrafluoroethylene (PTFE) membrane filter with a pore size of $0.2 \mu \mathrm{m}$ (ADVANTE $^{\circledR}$, Toyo Roshi Kaisha Ltd., Tokyo, Japan) using vacuum filtration. The filtrated CNF was then solvent exchanged from water to tert-butanol by immersing in tert-butanol for $30 \mathrm{~min}$. The solvent exchange procedure was repeated 6 times to fully exchange water with tert-butanol. After solvent exchange, CNF was freeze-dried (FDB-5503, Operon Co., Ltd., Gimpo, Korea) at $-55{ }^{\circ} \mathrm{C}$ for $2 \mathrm{~h}$. The freeze-dried CNFs were placed on aluminum stubs and then coated with iridium using a high-vacuum sputter coater (EMACE600, Leica Microsystems, Ltd., Wetzlar, Germany). The X-ray diffraction (XRD) patterns of the films were recorded on an X-Ray diffractometer (X'pert PRO MPD, PAN analytical: Netherland; operating voltage, $40 \mathrm{kV}$; current, $30 \mathrm{~mA}$ ) in the scan range of $10^{\circ}$ to $35^{\circ}$. The surface functional groups were probed by Fourier-transform infrared (FTIR) spectroscopy (Frontier, PerkinElmer; UK) in the range of $400-4000 \mathrm{~cm}^{-1}$ at a resolution of $1 \mathrm{~cm}^{-1}$. Light transmittance of the films was measured on a UV-Vis spectrometer (OPTIZEN POP-V, Daejon, 
Korea) with a wavelength range of $400-800 \mathrm{~nm}$. An empty cuvette was taken as a reference and the cut films were placed inside the cuvette and scanned.

\section{Results}

\subsection{Mechanical Properties}

Mechanical properties of CA/TC and CA/TA prepared using acetone as solvent at various ratios $(60 / 40,70 / 30,80 / 20)$ were first investigated to choose the best plasticizer content. Figure 1 shows the mechanical properties of CA/TC and CA/TA. As shown in the figure, the addition of both TA and TC plasticizers decreased the tensile strength and elastic modulus of the CA film but increased its elasticity. This result is similar to previous reports. $[15,16,18]$. In the research conducted by Phuong et al. in 2014, 20\% TA addition into CA obtained a tensile strength of $58.3 \mathrm{MPa}$, Elastic modulus of $3100 \mathrm{MPa}$, and elongation at break of $8.3 \%$; when TA concentration increased to $30 \%$, tensile strength decreased to 30.2 MPa, elastic Modulus decreased to $2100 \mathrm{GPa}$, and elongation at break increased to 11.6\% [16]. Meanwhile, in the research conducted by Park et al., 2014, 20\% TC addition into CA obtained a tensile strength of $70 \mathrm{MPa}$, Elastic modulus of $4100 \mathrm{MPa}$, and elongation at break of $8.5 \%$; when TC concentration increased to $30 \%$, tensile strength decreased to $61 \mathrm{MPa}$, Elastic modulus decreased to $2100 \mathrm{MPa}$, and elongation at break increased to $11.6 \%$ [11]. This can be explained because plasticizers (TA and TC) acted as a dilutor and lower the interaction of the molecules [29]. Based on this mechanical properties result, plasticizer content was fixed at $30 \%$ where elongation at break and tensile strength are in balance conditions. Both TC and TA were used in 30\% content as a plasticizer for CA film reinforced with CNF. The effect of solvent type was also varied; acetone and NMP were used as two different solvents. Mechanical properties of CA/TC/CNF and CA/TA/CNF with varied CNF content in acetone and NMP solvent are shown in Figure 2. CNF addition up to $5 \mathrm{phr}$ increased tensile strength and elastic modulus. Meanwhile, elongation break decreased with an increasing amount of CNF. The increase in elastic modulus is due to the presence of rigid nanoparticles from CNF. This shows that there is a stress transfer between CNF and CA matrix [30]. All samples with different plasticizer and solvent types showed the same patterns in mechanical properties. Similar results were also reported in a previous report by Leite et al., 2016, where $10 \%$ and $15 \%$ addition of CNC into CA increased elastic modulus up to $5 \%$ and $15 \%$ [30]. Research conducted by Azeredo et al. 2010 reported that $10 \% \mathrm{CNF}$ addition into chitosan increases tensile strength up to $16 \%$ [31].

Compared with plasticized CA without CNF, CA/TC/CNF in NMP solvent has shown the highest improvement in both tensile strengths from $34.2 \mathrm{MPa}$ to $47.6 \mathrm{MPa}(38 \%)$ and elastic modulus from $1649.1 \mathrm{MPa}$ to $2722.9 \mathrm{MPa}(65 \%)$. This is probably because of good dispersion of CNF in NMP, which is also evident from the better transparency of CA films (Figure 3).

\subsection{UV-Visible Spectroscopy}

Good transparency is one of the advantages of CA. Because of its high transparency, CA is used for several applications such as high-quality frames for sunglasses, personal protective equipment, and sports goggles [32]. Therefore, when reinforcement is added into $\mathrm{CA}$, it is expected that the transparency of CA could still be maintained. According to this result, NMP has become a possible alternative solvent to CA reinforced with CNF film for plastic application. Both TA and TC are clear colorless, thus the addition of plasticizers is not affecting the transparency of CA. UV-Visible spectroscopy was used to further compare film transparency. Figure 4 shows transmittance values of $68.7 \%, 64.9 \%, 67.7 \%, 63.4 \%$, and $55.3 \%$ for neat CA, CA/TC/CNF3 (Acetone), CA/TC/CNF3 (NMP), CA/TC/CNF10 (NMP), And CA/TC/CNF10 (Acetone), respectively. Compared with acetone, CA film prepared with NMP has better transparency due to better dispersion of CNF in NMP than in acetone. This result is also supported by the tensile properties result where CA film prepared with NMP had higher tensile properties compared with CA film prepared with acetone. 

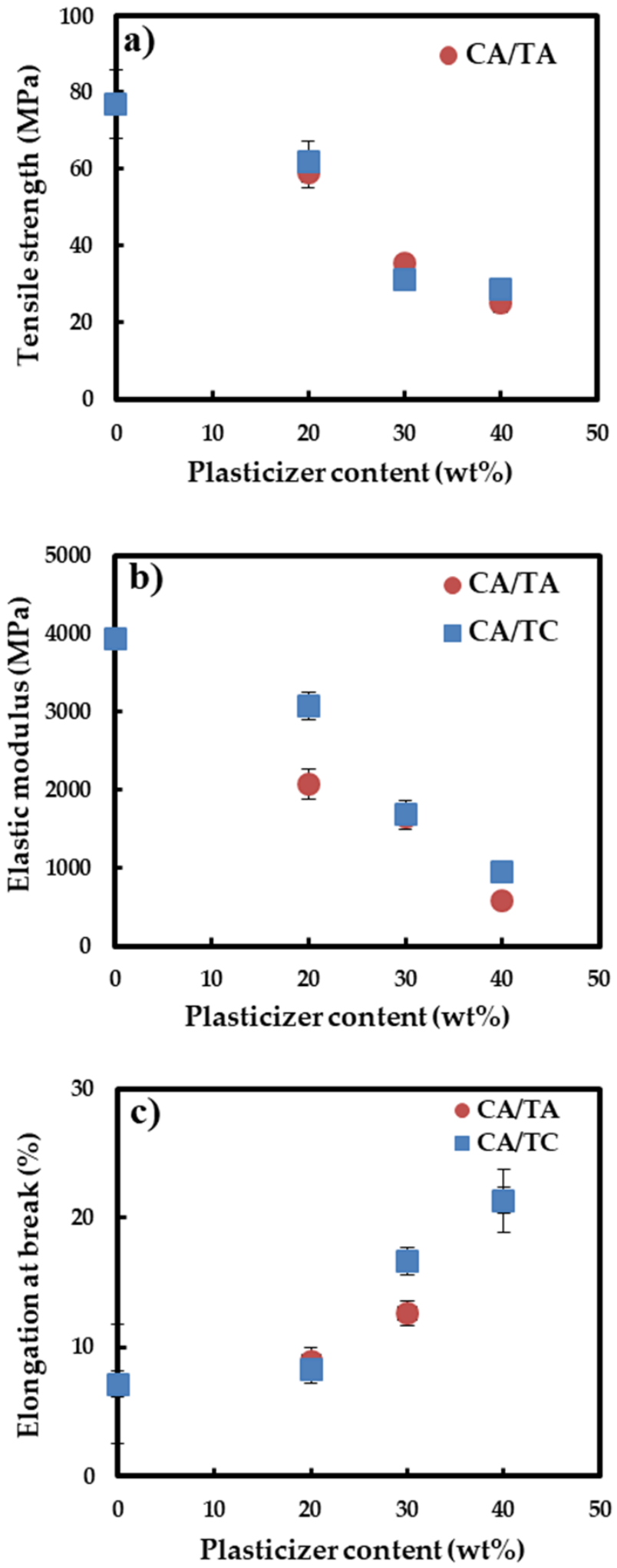

Figure 1. Tensile strength (a), elastic modulus (b), and elongation at break (c) of CA with TA and TC as a plasticizer in different ratios. 

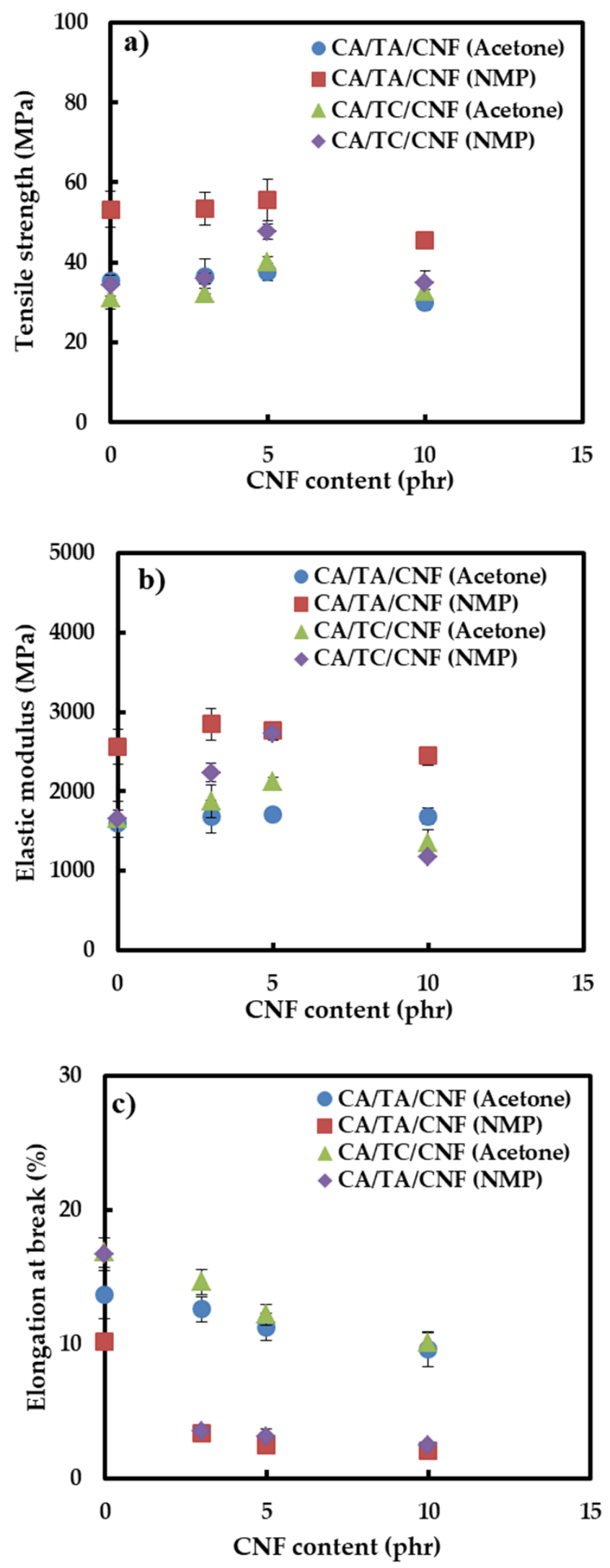

Figure 2. Tensile strength (a), elastic modulus (b), and elongation at break (c) of CA/TC/CNF and $\mathrm{CA} / \mathrm{TA} / \mathrm{CNF}$ in acetone and NMP solvent (Plasticizer content 30\%). 

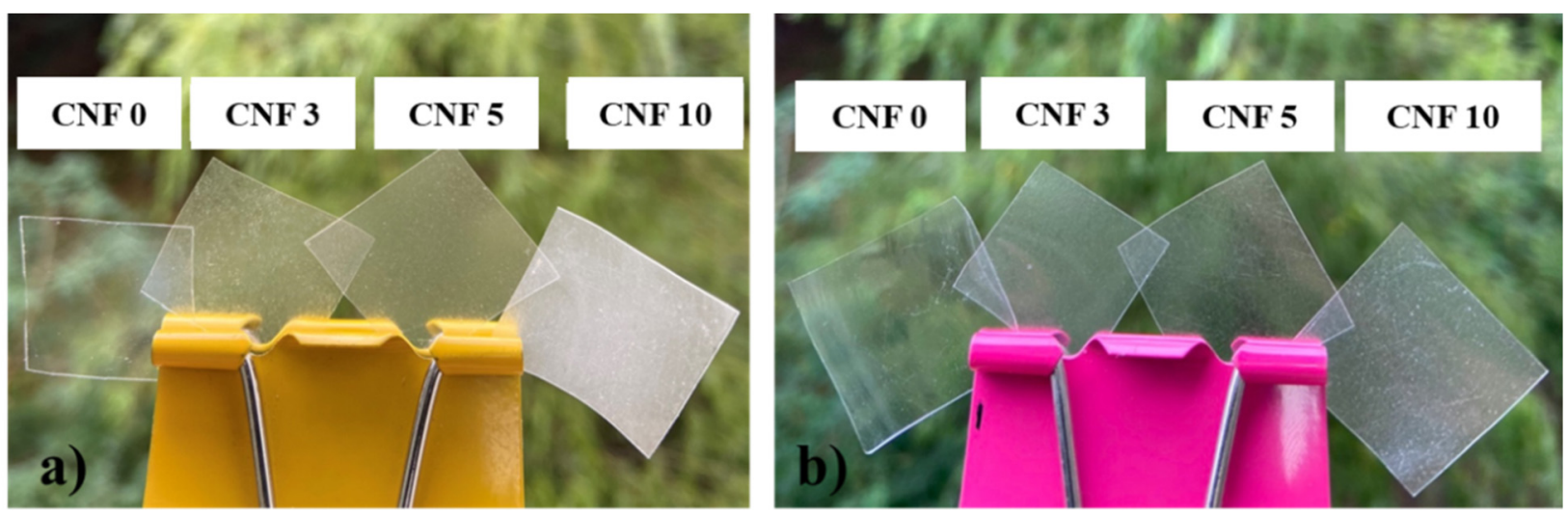

Figure 3. Digital photographs of plasticized CA/CNF films prepared in acetone (a) and NMP (b).

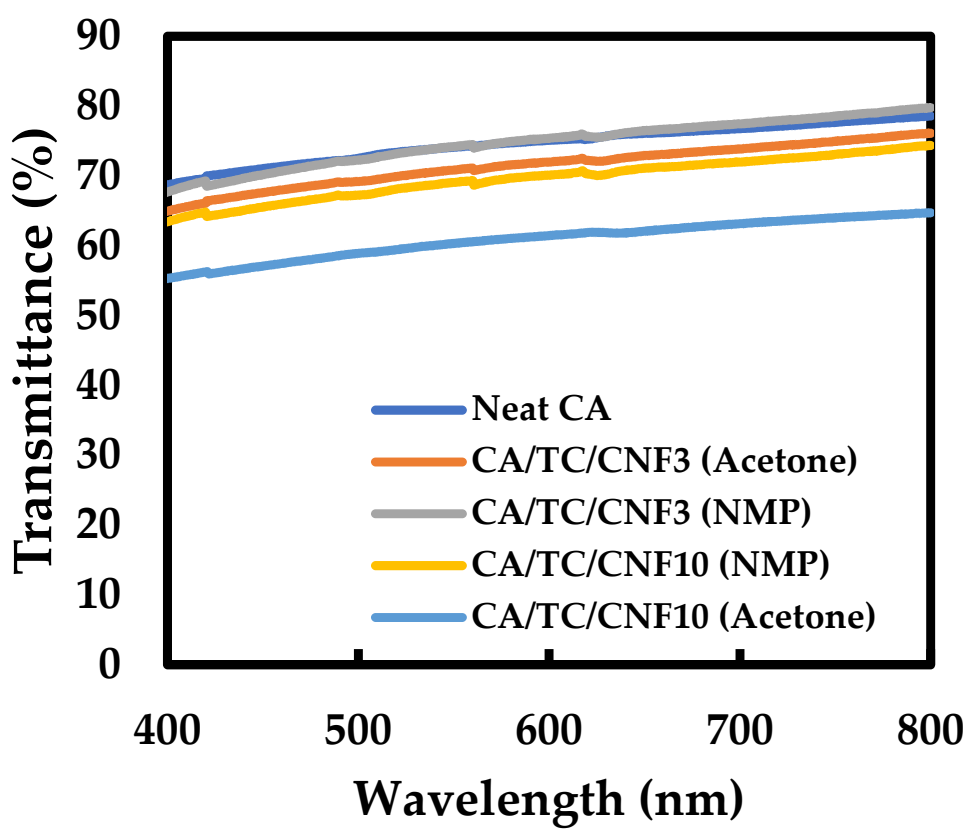

Figure 4. Visible light transmittance of CA films containing different ratios of CNF prepared using acetone and NMP solvent.

\subsection{Thermal Stability}

Figure 5 shows the thermal degradation behavior of Neat CA, CA/TC, and CA/TC/CNF5 in both acetone and NMP solvent. Thermal degradation behavior was investigated by Thermogravimetric analysis. Neat CA film showed two stages of degradation behavior. The first stage at $100{ }^{\circ} \mathrm{C}$ can be attributed to the evaporation of water. The second stage starting from $320{ }^{\circ} \mathrm{C}$ to $400{ }^{\circ} \mathrm{C}$ can be attributed to the thermal degradation of acetate functional groups and glucose rings in the polymer chain [12,33]. With the presence of TC plasticizer in CA film (CA/TC), thermal degradation behavior was changed from two stages to three stages. The first degradation stage corresponds to the evaporation of water, whereas the second stage at around $230^{\circ} \mathrm{C}$ is attributed to TC degradation [9]. The third stage at around $350{ }^{\circ} \mathrm{C}$ to $400{ }^{\circ} \mathrm{C}$ is attributed to the degradation of CA. This indicates that there is a physical interaction between CA and TC [11]. CA/TC/CNF5 has shown similar behavior in thermal degradation with three stages of degradation. However, the first degradation temperature is lower than CA/TC film. This might be because the interaction between TC and CA was reduced with the presence of CNF. In terms of solvent variation, NMP showed a slightly higher thermal stability than acetone. This is probably because NMP has a higher boiling point compared with acetone. 

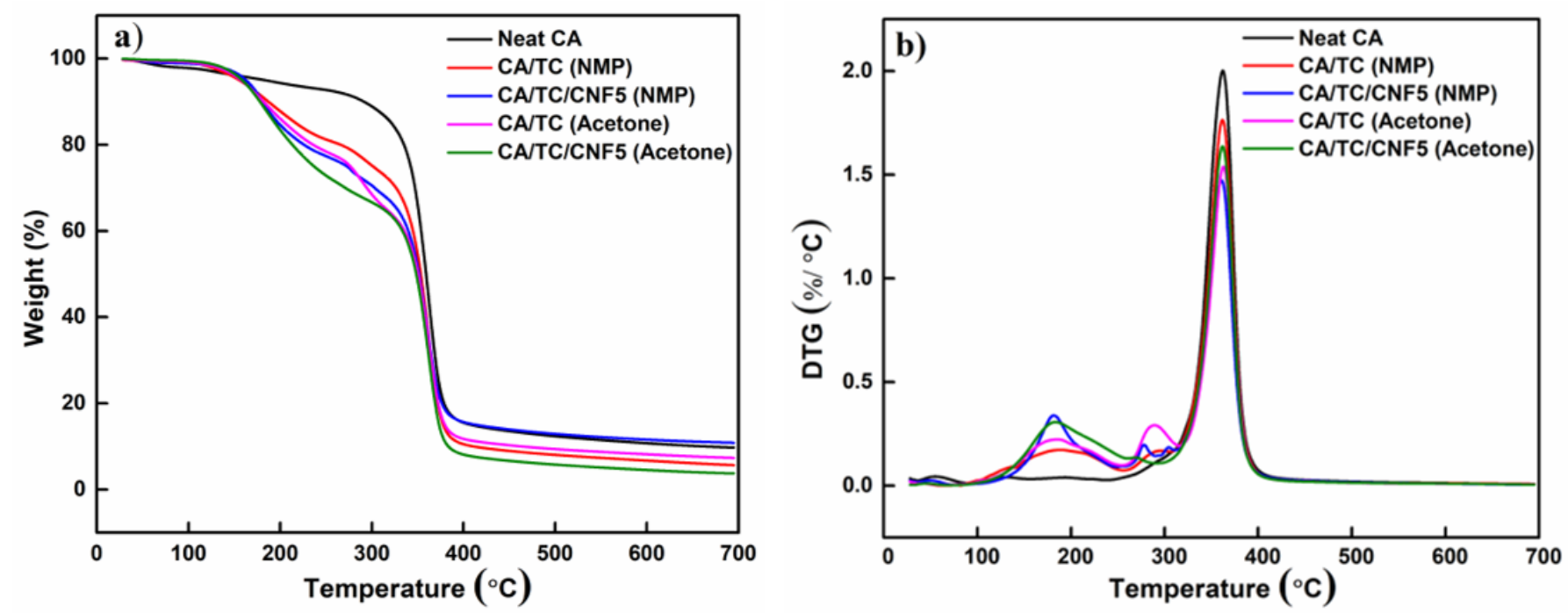

Figure 5. TGA (a) and DTG (b) graph of neat CA, CA/TC, and CA/TC/CNF5 in both acetone and NMP solvent.

\subsection{Water Absorption}

Water absorption is one of the important parameters for biodegradable plastic. Biodegradable plastic should have fewer water absorption properties for its functions. Water absorption was obtained from $24 \mathrm{~h}$ immersion in distilled water according to ASTM D570. The water absorption result is shown in Figure 6. All samples showed an increase in the percentage of water absorption with the addition of CNF. The increase in water absorption is related to the increased hydrophilic properties of the film upon adding CNF which is highly hydrophilic [34]. The water absorption percentage was relatively small $(\leq 4.8 \%)$, and these results aligned with research conducted by Amri et al. 2021, where 0.5\% CNF addition into waterborne polyurethane polymer had water absorption less than 3.5\% [35]. This indicates the hydrophobic properties of the polymer still dominate the composite.

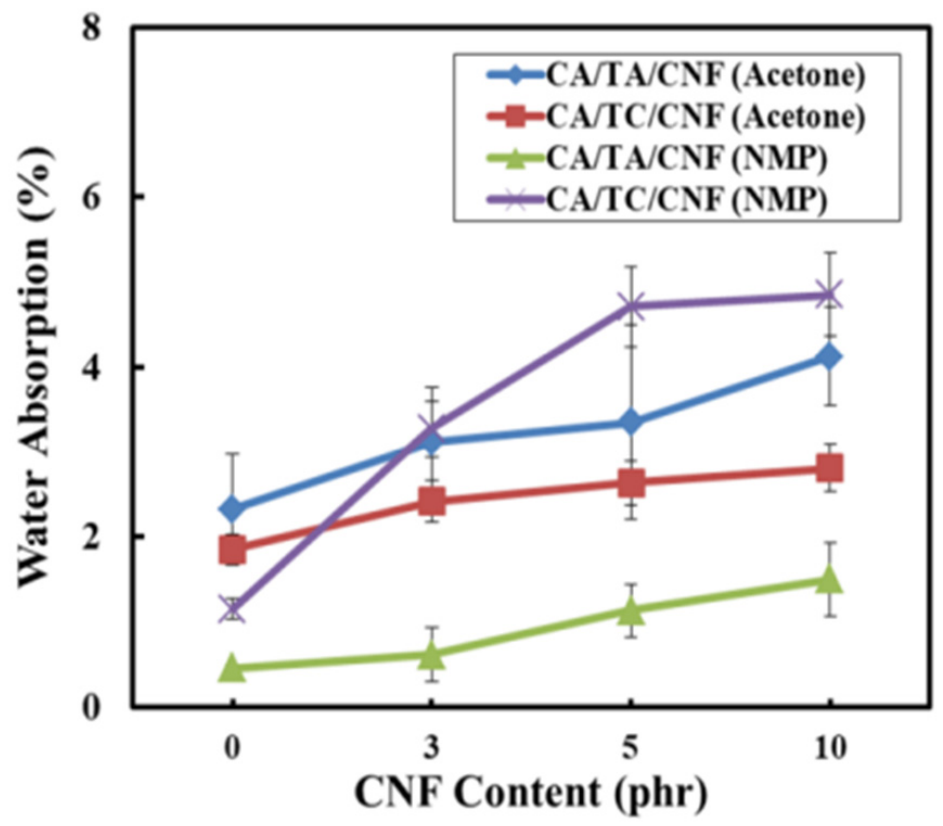

Figure 6. Water absorption of $\mathrm{CA} / \mathrm{TC} / \mathrm{CNF}$ and $\mathrm{CA} / \mathrm{TA} / \mathrm{CNF}$ with different $\mathrm{CNF}$ content prepared in both acetone and NMP solvent. 


\subsection{Viscosity}

Viscosity vs. shear rate curves are shown in Figure 7. CA fluid solution has shown typical curves of plastic fluid. The rheological behavior of other samples have shown a combination of non-Newtonian and Newtonian behavior. The viscosity of the solution was decreased at a lower shear rate; however, it was starting to be constant at the higher shear rate. A similar trend was also shown in research conducted by Park et al., 2021, where CNF was added into alginate (AL) [36]. This happened because with increasing shear rate, the polymer molecules start to untangle from each other and start to align them in the direction of flow, resulting in a decrease in viscosity.

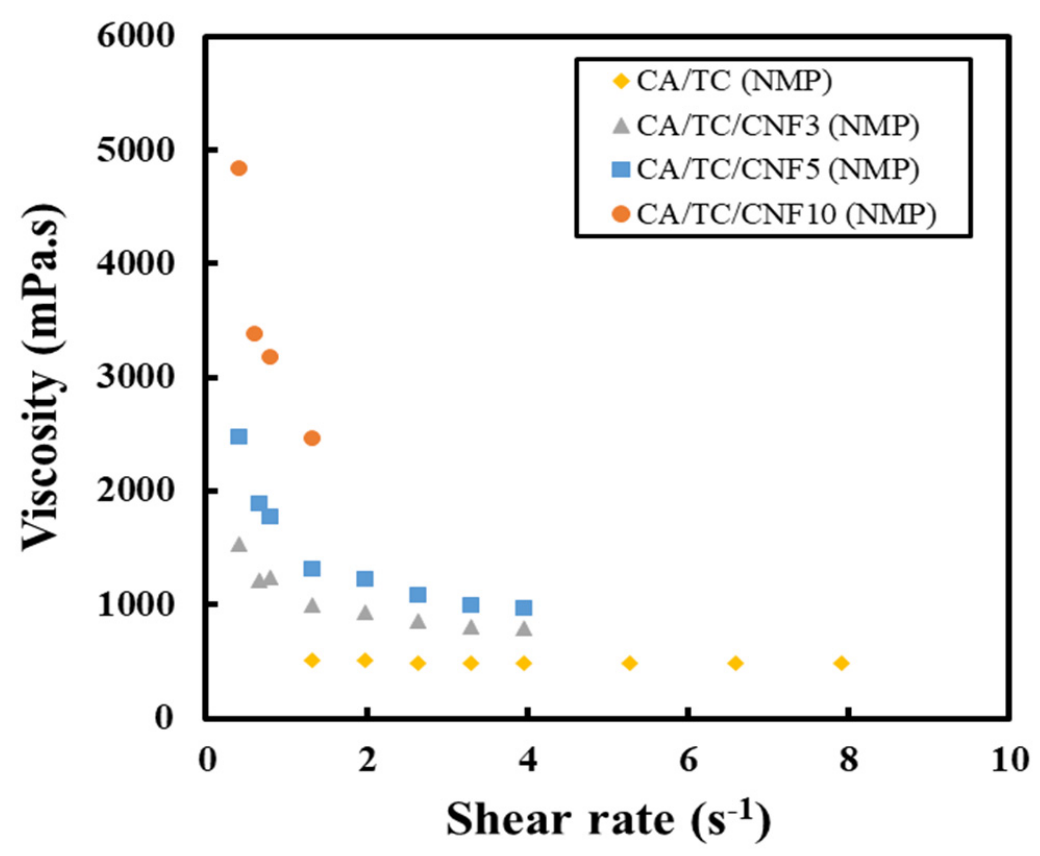

Figure 7. Viscosity of CA/TC and CA/TC/CNF with different CNF content in NMP solvent (Plasticizer content $30 \%$ ).

The effect of CNF amount on the viscosity of CA/TC/CNF in NMP solution is summarized in Table 2. The viscosity was increased with an increasing amount of CNF filler. The increase of viscosity upon the addition of CNF filler could indicate good dispersion of CNF in the CA matrix which leads to a good interaction between CNF and CA macromolecules [37].

Table 2. Viscosity of CA/TC and CA/TC/CNF solutions in NMP with different CNF content and shear rate at a concentration of $10 \mathrm{wt} \%$.

\begin{tabular}{ccccc}
\hline \multirow{2}{*}{ Sample Name } & \multirow{2}{*}{ CNF Content (phr) } & \multicolumn{3}{c}{ Viscosity (mPa.s) } \\
\cline { 3 - 5 } & & SR 0.79 s $\mathbf{~}^{-\mathbf{1}}$ & SR 1.32 s & SR 1.98 s \\
\hline CA/TC & 0 & N/A & 516 & 511 \\
CA/TC/CNF3 & 3 & 1245 & 996 & 935 \\
CA/TC/CNF5 & 5 & 1771 & 1314 & 1226 \\
CA/TC/CNF10 & 10 & 3185 & 2463 & N/A \\
\hline
\end{tabular}

\subsection{Morphological Observation}

Morphological observation from the fractured surface of CA film reinforced with CNF is shown in Figure 8. As shown in the images, the presence of CNF resulted in a drastic change in the structure of the CA composite. The CA composite with addition of $5 \%$ and $10 \% \mathrm{CNF}$ had a rough structure in the fractured surfaces area. Meanwhile, the fractured surface of neat CA was smooth. The effect of solvent on the morphological 
characteristic was also studied, and CA/TC/CNF5 with NMP solvent showed less rough structure compared with acetone, even with a higher $\mathrm{CNF}$ content of $10 \%$. SEM images of the surface area of neat CA, CA composite, and CNF are shown in Figure 9. As shown in the figure, Neat CA showed a very smooth surface area. Meanwhile, apart from CA, composite films exhibited a little aggregation of $\mathrm{CNF}$, shown as white spots in the surface area, indicating the presence of CNF in CA film.
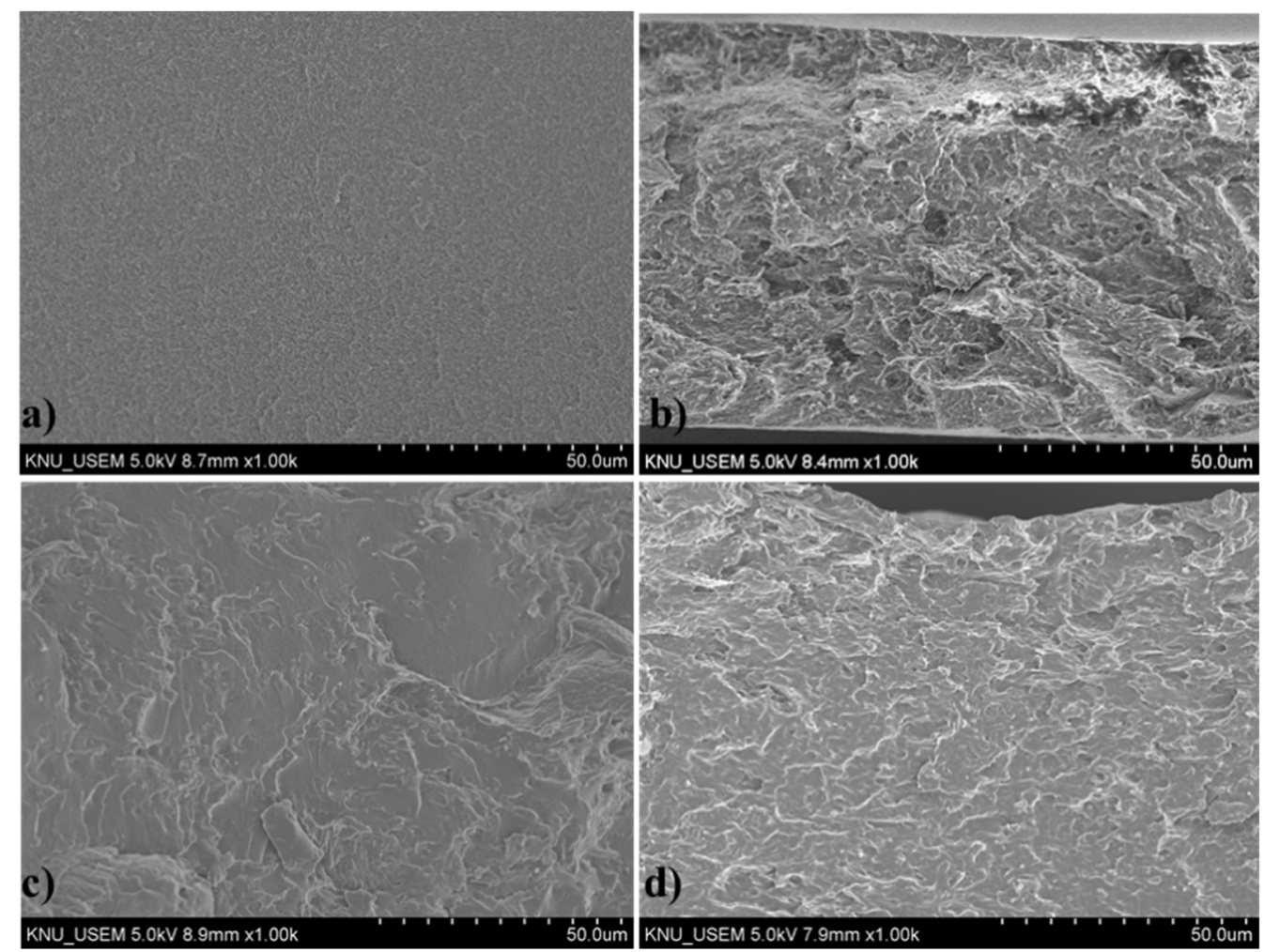

Figure 8. SEM images of the fractured surface of Neat CA (a), CA/TC/CNF5 (Acetone) (b), $\mathrm{CA} / \mathrm{TC} / \mathrm{CNF} 5$ (NMP) (c), and CA/TC/CNF10 (NMP) (d).

\subsection{XRD and FTIR}

XRD patterns of neat CA, CA/TC, CA/TC/CNF5, and CA/TC/CNF10 in NMP solvent are shown in Figure 10a. Neat CA exhibited weak cellulose peaks at $2 \theta=18-22^{\circ}$. This is because CA has a substitution degree at $~ 2.5$ where most of the hydroxyl group on cellulose are replaced with acetyl groups. As a result, intermolecular hydrogen bonding is absent or minimal, destroying the ordered crystalline structure [38]. Addition of TC caused no significant difference. However, the addition of CNF into CA matrix slightly increased the intensity of the peak in the $2 \theta=18-22^{\circ}$ range. No significant cellulosic peak was observed at $2 \theta=18-22^{\circ}$, even at high CNF content (CA/TC/CNF10), indicating the CNF is uniformly distributed throughout the CA matrix. Figure 10b shows the FTIR spectra of neat CA, CA/TC, CA/TC/CNF5, and CA/TC/CNF10 in NMP solvent. For neat CA, the peak at $3470 \mathrm{~cm}^{-1}$ can be attributed to the $\mathrm{O}-\mathrm{H}$ bond stretching, and the peak at $2924 \mathrm{~cm}^{-1}$ is for $\mathrm{C}-\mathrm{H}$ stretching. The characteristic peak at $1730 \mathrm{~cm}^{-1}$ is assigned for carbonyl stretch of the acetate function and the peak at $1367 \mathrm{~cm}^{-1}$ can be assigned to $\mathrm{C}-\mathrm{H}$ bending. Peaks at $1215 \mathrm{~cm}^{-1}$ and $1028 \mathrm{~cm}^{-1}$ can be ascribed to C-O stretch in C-O-H and in the C-O-C group respectively [1]. No significant changes in the peaks were observed after the addition of TC and CNF. Only a slight change in the intensity and shape of C-O peak at $1215 \mathrm{~cm}^{-1}$ was observed. This might be due to their uniform distribution and low loading content. 

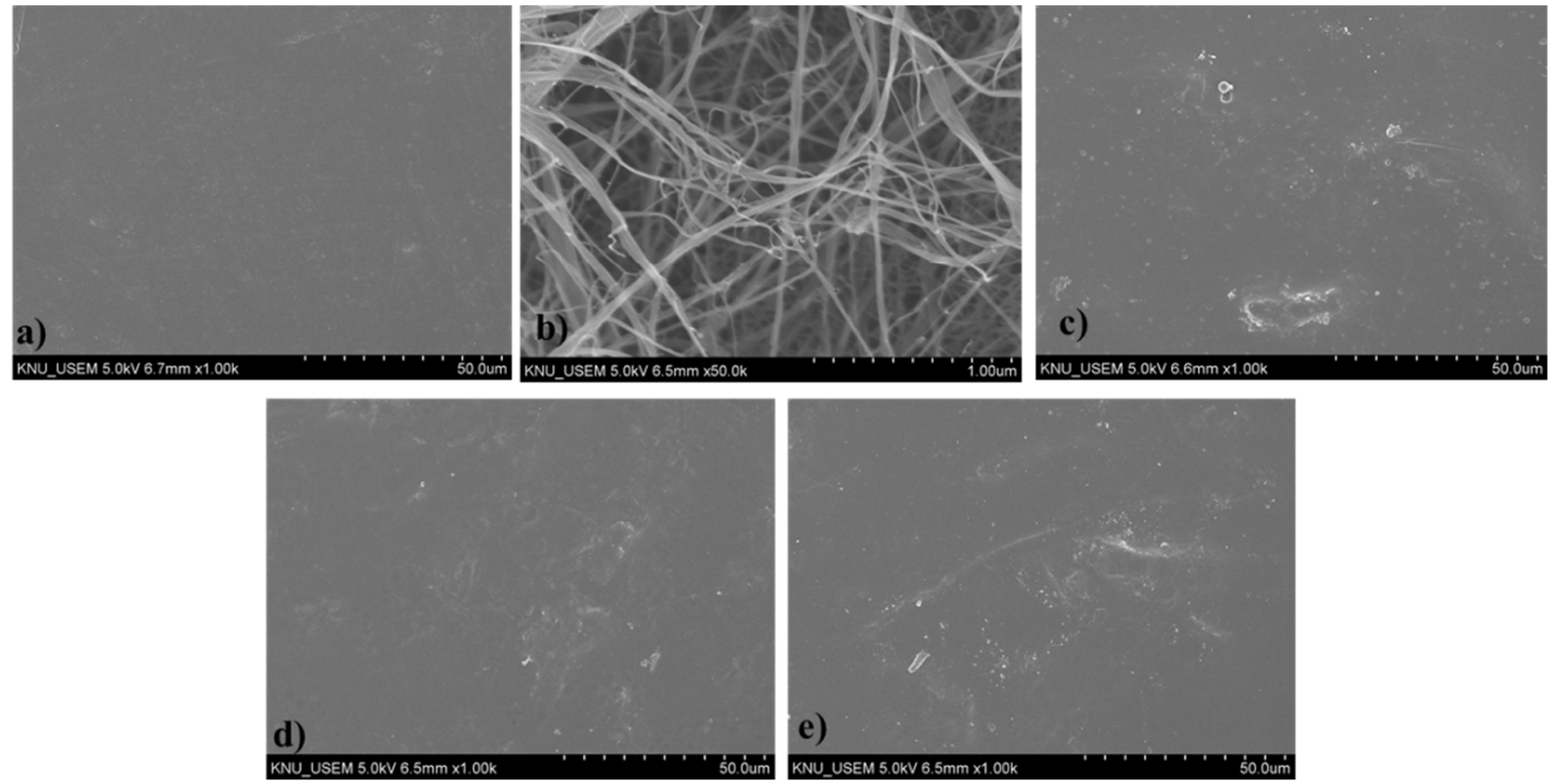

Figure 9. SEM images of Neat CA (a), CNF (b), CA/TC/CNF5 (Acetone) (c), CA/TC/CNF5 (NMP) (d), and CA/TC/CNF10 (NMP) (e).
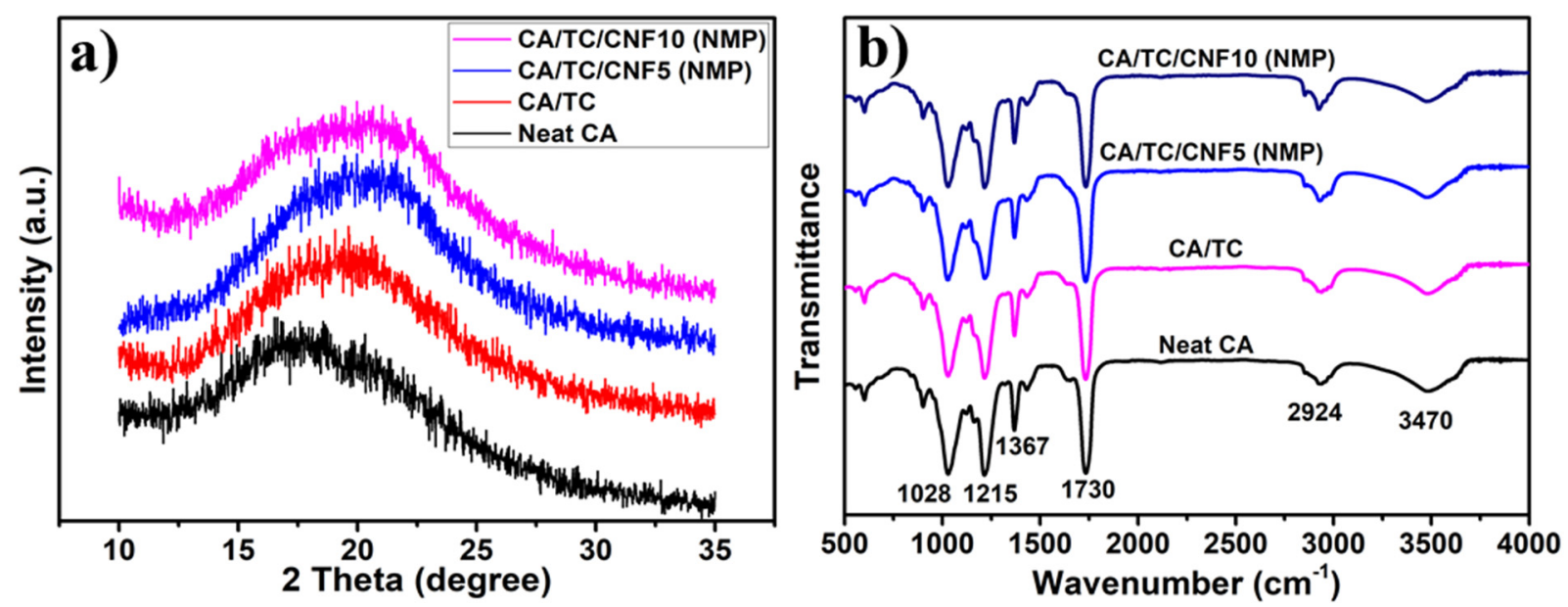

Figure 10. XRD patterns (a) and FTIR spectra (b) of Neat CA, CA/TC, CA/TC/CNF5 (NMP) and CA/TC/CNF10 (NMP).

\section{Conclusions}

CA film was successfully prepared with CNF as reinforcement. Two different kinds of plasticizers, TA and TC, and two different kinds of solvents, acetone and NMP, were used. For both TA and TC, 30\% content was chosen as the optimal condition for CA. When plasticizer content was more than $30 \%$, tensile and elastic modulus properties of the CA film became unacceptably low. The presence of plasticizer in CA films changed the thermal degradation behavior of $\mathrm{CA}$ from two stages into three stages, also reducing film stiffness. The addition of up to $5 \mathrm{phr}$ CNF into the CA matrix increased the tensile properties of the composite. However, the tensile strength was decreased with $10 \mathrm{phr} C \mathrm{NF}$ addition. The highest improvement in tensile strength and elastic modulus was gained by using NMP as a solvent because of better dispersion of CNF in NMP than in acetone. NMP was found to be a good solvent for the CA/CNF composite with higher tensile properties. Tensile strength and elastic modulus increased up to $38 \%$ and $65 \%$, respectively. The use of CNF 
as reinforcement and TC and TA as eco-friendly plasticizer can expand the application of CA into wider applications, such as food packaging.

Author Contributions: Data curation, A.W.C., G.-J.K.; methodology, A.W.C., C.-W.P.; resources, J.-S.P., E.-A.L., J.-K.K.; project administration, S.-Y.H.; supervision, S.-H.L.; writing—original draft, A.W.C.; writing-review and editing, R.B. All authors have read and agreed to the published version of the manuscript.

Funding: This research was supported by Basic Science Research Program through the National Research Foundation of Korea (NRF), funded by the Ministry of Education (No.2018R1A6A1A03025582, No. 2021R1A2C2004941).

Institutional Review Board Statement: Not applicable.

Data Availability Statement: Data is available upon request from the corresponding author.

Conflicts of Interest: The authors declare no conflict of interest.

\section{References}

1. Wang, B.; Chen, J.; Peng, H.; Gai, J.; Kang, J.; Cao, Y. Investigation on Changes in the Miscibility, Morphology, Rheology and Mechanical Behavior of Melt Processed Cellulose Acetate through Adding Polyethylene Glycol as a Plasticizer. J. Macromol. Sci. Part B Phys. 2016, 55, 894-907. [CrossRef]

2. Ezugbe, E.O.; Rathilal, S. Membrane technologies in wastewater treatment: A review. Membranes 2020, 10, 89. [CrossRef]

3. Thakur, V.K.; Voicu, S.I. Recent advances in cellulose and chitosan based membranes for water purification: A concise review. Carbohydr. Polym. 2016, 146, 148-165. [CrossRef]

4. Căprărescu, S.; Zgârian, R.G.; Tihan, G.T.; Purcar, V.; Totu, E.E.; Modrogan, C.; Chiriac, A.L.; Nicolae, C.A. Biopolymeric membrane enriched with chitosan and silver for metallic ions removal. Polymers 2020, 12, 1792. [CrossRef] [PubMed]

5. Saha, N.R.; Sarkar, G.; Roy, I.; Bhattacharyya, A.; Rana, D.; Dhanarajan, G.; Banerjee, R.; Sen, R.; Mishra, R.; Chattopadhyay, D. Nanocomposite films based on cellulose acetate/polyethylene glycol/modified montmorillonite as nontoxic active packaging material. RSC Adv. 2016, 6, 92569-92578. [CrossRef]

6. Felgueiras, C.; Azoia, N.G.; Gonçalves, C.; Gama, M.; Dourado, F. Trends on the Cellulose-Based Textiles: Raw Materials and Technologies. Front. Bioeng. Biotechnol. 2021, 9, 202. [CrossRef] [PubMed]

7. Bifari, E.N.; Bahadar Khan, S.; Alamry, K.A.; Asiri, A.M.; Akhtar, K. Cellulose Acetate Based Nanocomposites for Biomedical Applications: A Review. Curr. Pharm. Des. 2016, 22, 3007-3019. [CrossRef] [PubMed]

8. Najafi, M.; Sadeghi, M.; Bolverdi, A.; Pourafshari Chenar, M.; Pakizeh, M. Gas permeation properties of cellulose acetate/silica nanocomposite membrane. Adv. Polym. Technol. 2018, 37, 2043-2052. [CrossRef]

9. Wsoo, M.A.; Shahir, S.; Mohd Bohari, S.P.; Nayan, N.H.M.; Razak, S.I.A. A review on the properties of electrospun cellulose acetate and its application in drug delivery systems: A new perspective. Carbohydr. Res. 2020, 491, 107978. [CrossRef]

10. Charvet, A.; Vergelati, C.; Long, D.R. Mechanical and ultimate properties of injection molded cellulose acetate/plasticizer materials. Carbohydr. Polym. 2019, 204, 182-189. [CrossRef] [PubMed]

11. Phuong, V.T.; Lazzeri, A. "green" biocomposites based on cellulose diacetate and regenerated cellulose microfibers: Effect of plasticizer content on morphology and mechanical properties. Compos. Part A Appl. Sci. Manuf. 2012, 43, 2256-2268. [CrossRef]

12. Dreux, X.; Majesté, J.C.; Carrot, C.; Argoud, A.; Vergelati, C. Viscoelastic behaviour of cellulose acetate/triacetin blends by rheology in the melt state. Carbohydr. Polym. 2019, 222, 114973. [CrossRef]

13. El-Rehim, H.A.; Kamal, H.; Hegazy, E.S.A.; Soliman, E.S.; Sayed, A. Use of gamma rays to improve the mechanical and barrier properties of biodegradable cellulose acetate nanocomposite films. Radiat. Phys. Chem. 2018, 153, 180-187. [CrossRef]

14. Teixeira, S.C.; Silva, R.R.A.; de Oliveira, T.V.; Stringheta, P.C.; Pinto, M.R.M.R.; Soares, N.d.F.F. Glycerol and triethyl citrate plasticizer effects on molecular, thermal, mechanical, and barrier properties of cellulose acetate films. Food Biosci. 2021, 42, 101202. [CrossRef]

15. Bao, C. Cellulose Acetate/Plasticizer Systems: Structure, Morphology and Dynamics. Ph.D. Thesis, Universite Claude BernardLyon I, Villeurbanne, France, 2015; pp. 1-197.

16. Lee, S.H.; Shiraishi, N. Plasticization of cellulose diacetate by reaction with maleic anhydride, glycerol, and citrate esters during melt processing. J. Appl. Polym. Sci. 2001, 81, 243-250. [CrossRef]

17. Phuong, V.T.; Verstichel, S.; Cinelli, P.; Anguillesi, I.; Coltelli, M.B.; Lazzeri, A. Cellulose acetate blends -effect of plasticizers on properties and biodegradability. J. Renew. Mater. 2014, 2, 35-41. [CrossRef]

18. Park, H.M.; Misra, M.; Drzal, L.T.; Mohanty, A.K. “Green” nanocomposites from cellulose acetate bioplastic and clay: Effect of eco-friendly triethyl citrate plasticizer. Biomacromolecules 2004, 5, 2281-2288. [CrossRef]

19. Iryani, D.A.; Wulandari, N.F.; Cindradewi, A.W.; Ginting, S.B.; Ernawati, E.; Hasanudin, U. Lampung natural zeolite filled cellulose acetate membrane for pervaporation of ethanol-water mixtures. In IOP Conference Series: Earth and Environmental Science; IOP Publishing: Bristol, UK, 2018; Volume 141, p. 012013. 
20. Xia, Z.; Li, J.; Zhang, J.; Zhang, X.; Zheng, X.; Zhang, J. Processing and valorization of cellulose, lignin and lignocellulose using ionic liquids. J. Bioresour. Bioprod. 2020, 5, 79-95. [CrossRef]

21. Lee, S.-H.; Kim, H.-J.; Kim, J.-C. Nanocellulose Applications for Drug Delivery: A Review. J. For. Environ. Sci. 2019, 35, 141-149.

22. Zou, Y.; Zhao, J.; Zhu, J.; Guo, X.; Chen, P.; Duan, G.; Liu, X.; Li, Y. A Mussel-Inspired Polydopamine-Filled Cellulose Aerogel for Solar-Enabled Water Remediation. ACS Appl. Mater. Interfaces 2021, 13, 7617-7624. [CrossRef] [PubMed]

23. Joseph, B.; Sagarika, V.K.; Sabu, C.; Kalarikkal, N.; Thomas, S. Cellulose nanocomposites: Fabrication and biomedical applications. J. Bioresour. Bioprod. 2020, 5, 223-237. [CrossRef]

24. Oksman, K.; Aitomäki, Y.; Mathew, A.P.; Siqueira, G.; Zhou, Q.; Butylina, S.; Tanpichai, S.; Zhou, X.; Hooshmand, S. Review of the recent developments in cellulose nanocomposite processing. Compos. Part A Appl. Sci. Manuf. 2016, 83, 2-18. [CrossRef]

25. van der Berg, O.; Capadona, J.R.; Weder, C. Preparation of homogeneous dispersions of tunicate cellulose whiskers in organic solvents. Biomacromolecules 2007, 8, 1353-1357. [CrossRef]

26. Viet, D.; Beck-Candanedo, S.; Gray, D.G. Dispersion of cellulose nanocrystals in polar organic solvents. Cellulose 2007, 14, 109-113. [CrossRef]

27. Astm ASTM D638: Standard Test Method for Tensile Properties of Plastics; American Society for Testing and Materials: West Conshohocken, PA, USA, 2004; pp. 1-15.

28. ASTM International ASTM D570—Standard Test for Water Absorption of Plastics; American Society for Testing and Materials: West Conshohocken, PA, USA, 2010; Volume 98, pp. 1-4.

29. Kormin, S.; Kormin, F.; Beg, M.D.H. Effect of plasticizer on physical and mechanical properties of ldpe/sago starch blend. In Journal of Physics: Conference Series; IOP Publishing: Bristol, UK, 2019; Volume 1150, p. 012032.

30. Leite, L.S.F.; Battirola, L.C.; da Silva, L.C.E.; Gonçalves, M.d.C. Morphological investigation of cellulose acetate/cellulose nanocrystal composites obtained by melt extrusion. J. Appl. Polym. Sci. 2016, 133, 44201. [CrossRef]

31. Azeredo, H.M.C.; Mattoso, L.H.C.; Avena-Bustillos, R.J.; Filho, G.C.; Munford, M.L.; Wood, D.; McHugh, T.H. Nanocellulose reinforced chitosan composite films as affected by nanofiller loading and plasticizer content. J. Food Sci. 2010, 75, N1-N7. [CrossRef]

32. Introduction to Bioplastics Engineering; Elsevier: Amsterdam, The Netherlands, 2016.

33. Gwon, J.G.; Lee, D.B.; Cho, H.J.; Lee, S.Y. Preparation and characteristics of cellulose acetate based nanocomposites reinforced with cellulose nanocrystals (CNCs). J. Korean Wood Sci. Technol. 2018, 46, 565-576.

34. Kahavita, K.D.H.N.; Samarasekara, A.M.P.B.; Amarasinghe, D.A.S.; Karunanayake, L. Influence of Surface Modification of Cellulose Nanofibers (CNF) as the Reinforcement of Polypropylene Based Composite. In Proceedings of the MERCon 2019_-Proceedings, 5th International Multidisciplinary Moratuwa Engineering Research Conference, Moratuwa, Sri Lanka, 3-5 July 2019; Institute of Electrical and Electronics Engineers Inc.: Piscataway, NJ, USA, 2019; pp. 99-104.

35. Amri, M.R.; Guan, C.T.; Osman Al-Edrus, S.S.; Yasin, F.M.; Mohamad, S.F. Effect of cellulose nanofibrils on the properties of jatropha oil-basedwaterborne polyurethane nanocomposite film. Polymers 2021, 13, 1460. [CrossRef] [PubMed]

36. Park, J.S.; Park, C.W.; Han, S.Y.; Lee, E.A.; Cindradewi, A.W.; Kim, J.K.; Kwon, G.J.; Seo, Y.H.; Yoo, W.J.; Gwon, J.Y.; et al. Preparation and properties of wet-spun microcomposite filaments from various cnfs and alginate. Polymers 2021, 13, 1709. [CrossRef]

37. Marquez-Bravo, S.; Doench, I.; Molina, P.; Bentley, F.E.; Tamo, A.K.; Passieux, R.; Lossada, F.; David, L.; Osorio-Madrazo, A. Functional bionanocomposite fibers of chitosan filled with cellulose nanofibers obtained by gel spinning. Polymers 2021, 13, 1563. [CrossRef]

38. Lu, J.; Drzal, L.T. Microfibrillated cellulose/cellulose acetate composites: Effect of surface treatment. J. Polym. Sci. Part B Polym. Phys. 2010, 48, 153-161. [CrossRef] 